\title{
Should pylorus-preserving gastrectomy be performed for overweight/ obese patients with gastric cancer?
}

\author{
Masahiro Tsujiura ${ }^{1} \cdot$ Naoki Hiki $^{1} \cdot$ Manabu Ohashi $^{1}$ - Souya Nunobe ${ }^{1} \cdot$ Koshi Kumagai $^{1}$ - Satoshi Ida ${ }^{1}$. \\ Takuma Ohashi $^{1} \cdot$ Takeshi Sano $^{1} \cdot$ Toshiharu Yamaguchi $^{1}$
}

Received: 11 October 2018 / Accepted: 9 March 2019 / Published online: 19 March 2019

(c) The International Gastric Cancer Association and The Japanese Gastric Cancer Association 2019

\begin{abstract}
Background Pylorus-preserving gastrectomy is an alternative to distal gastrectomy for early gastric cancer, and is expected to have postoperative advantages including maintenance of body weight. Overweight/obesity is a risk factor for chronic disorders, including hypertension and diabetes mellitus; in these conditions, body weight control is frequently required as part of treatment. It remains unknown whether pylorus-preserving gastrectomy should be performed in overweight/obese patients because excess body weight may be maintained postoperatively.

Methods We retrospectively investigated body weight changes and postoperative nutritional status of overweight/obese patients who underwent laparoscopic distal gastrectomy (LDG) or laparoscopic pylorus-preserving gastrectomy (LPPG) between 2006 and 2015. Among 349 overweight patients (BMI $\geq 25 \mathrm{~kg} / \mathrm{m}^{2}$ ), $101 \mathrm{LDG}$ and $101 \mathrm{LPPG}$ cases were compared after propensity score matching to adjust for patient characteristics.

Results The mean relative body weight ratios (postoperative/preoperative ratios) were $87.5 \pm 8.0 \%$ after LDG and $89.6 \pm 6.7 \%$ after LPPG (difference not significant, $p=0.088$ ). The prealbumin level at 2 years and hemoglobin levels at 6 months, 1 year and 2 years were significantly well maintained after LPPG than after LDG. Prealbumin and hemoglobin levels at 2 years had almost returned to baseline levels in the LPPG group. The superiority of LPPG in the hemoglobin level was confirmed regardless of reconstruction methods after LDG.

Conclusions For overweight/obese patients, LDG and LPPG resulted in similar degrees of postoperative weight loss, with patients achieving near-ideal body weight. The postoperative nutritional advantages of LPPG were confirmed. LPPG seemed to be better even for overweight/obese patients who meet indication criteria.
\end{abstract}

Keywords Gastric cancer · Laparoscopic pylorus-preserving gastrectomy · Overweight patient $\cdot$ Propensity score matching

$\begin{array}{ll}\text { Abbreviations } \\ \text { ASA-PS } & \begin{array}{l}\text { American Society of Anesthesiologists physical } \\ \text { status }\end{array} \\ \text { (B1) } & \text { Billroth I } \\ \text { BMI } & \text { Body mass index } \\ \text { DG } & \text { Distal gastrectomy } \\ \text { GC } & \text { Gastric cancer }\end{array}$

Electronic supplementary material The online version of this article (https://doi.org/10.1007/s10120-019-00951-x) contains supplementary material, which is available to authorized users.

Naoki Hiki

naoki.hiki@jfcr.or.jp

1 Department of Gastroenterological Surgery,

Gastroenterological Center, Cancer Institute Hospital,

Japanese Foundation for Cancer Research, 3-8-31 Ariake,

Koto-ward, 135-8550 Tokyo, Japan
LDG Laparoscopic distal gastrectomy

LPPG Laparoscopic pylorus-preserving gastrectomy

PPG Pylorus-preserving gastrectomy

PSM Propensity score matching

(RY) Roux-en-Y

\section{Introduction}

Pylorus-preserving gastrectomy (PPG) is a major functionpreserving procedure and is an alternative to distal gastrectomy (DG) for early gastric cancer in the middle third of the stomach [1]. PPG has several functional advantages and a lower incidence of postgastrectomy syndromes such as dumping syndrome and bile reflux, compared with conventional DG with Billroth I reconstruction [2-4]. Additionally, several studies have demonstrated that patients who undergo 
PPG have better postoperative nutritional status and bodyweight maintenance compared with patients following other types of gastrectomy [5-8].

Overweight/obesity is among the most important growing health issues worldwide and is associated with various health problems, including cardiovascular and kidney disorders, hypertension and diabetes mellitus [9-12]. Body weight control is frequently required in the treatment of obese patients with these chronic lifestyle-related diseases $[13,14]$. It remains unknown whether PPG should be performed in overweight/obese patients because excess body weight may be maintained postoperatively.

Recently, some groups have reported that overweight/ obese patients with gastric cancer (GC) tend to have greater postoperative weight loss than other patients. In an Asian series, Kong et al. [15] found that overweight patients (body mass index $[\mathrm{BMI}] \geq 25 \mathrm{~kg} / \mathrm{m}^{2}$ ) were likely to lose excessive body weight and to achieve ideal body weight after curative gastrectomy. In a Western series, Davis et al. [16] reported that the extent of weight loss after gastrectomy for GC was associated with preoperative BMI $\left(\geq 30 \mathrm{~kg} / \mathrm{m}^{2}\right.$ versus $<30 \mathrm{~kg} / \mathrm{m}^{2}$ ) as well as extent of gastric resection (total versus subtotal). However, those reports were based on clinical data after standard gastrectomy for GC. Body weight change after modified function-preserving procedures such as PPG in overweight/obese patients has not been reported to date. At our institution, we have proactively adopted laparoscopic PPG (LPPG) for patients with clinically diagnosed early gastric cancer in the middle third of the stomach, regardless of preoperative BMI. Using the accumulated clinical data from overweight/obese patients, we aimed to compare surgical outcomes following LPPG versus laparoscopic DG (LDG) in patients with $\mathrm{BMI} \geq 25 \mathrm{~kg} / \mathrm{m}^{2}$. We compared postoperative nutritional status and body weight change between the groups after adjusting for patient characteristics with propensity score matching (PSM).

\section{Methods}

\section{Study design and patient selection}

Between January 2006 and December 2015, a total of 1655 patients underwent LDG $(n=1017)$ or LPPG $(n=638)$ at our institution for cStage I GC. These populations included both non-overweight (BMI $\left.<25 \mathrm{~kg} / \mathrm{m}^{2}, n=1306\right)$ and overweight (BMI $\geq 25 \mathrm{~kg} / \mathrm{m}^{2}, n=349$ ) patients. Among the 349 patients with $\mathrm{BMI} \geq 25 \mathrm{~kg} / \mathrm{m}^{2}, 36$ were excluded from further analysis because they had other malignancies, received adjuvant chemotherapy or died/relapsed postoperatively. PSM was performed with the remaining overweight patients to improve comparability between LDG and LPPG groups. The propensity score model was created using logistic regression analysis with the following variables: sex, age, BMI, histological type and American Society of Anesthesiologists physical status (ASA-PS) score. Nearest-neighbor matching was performed with a caliper width of 0.2 standard deviations of the logit of the estimated propensity score at a ratio of $1: 1$ without replacement. The laboratory data and body weight change of 202 propensity score-matched patients (LDG: $n=101$; LPPG: $n=101$ ) were analyzed in the current study (Fig. 1).
Fig. 1 Study flow chart; a total of 1665 patients, who underwent LDG or LPPG for cStage I GC between 2006 and 2015 , were categorized to non-overweight (BMI $<25 \mathrm{~kg}$ ) $\left.\mathrm{m}^{2}, n=1306\right)$ and overweight (BMI $\geq 25 \mathrm{~kg} / \mathrm{m}^{2}, n=349$ ). After exclusion of 36 cases, an adjustment by propensity score matching was performed. Finally, 202 overweight cases (LDG; $n=101$, LPPG; $n=101$ ) were analyzed in this study

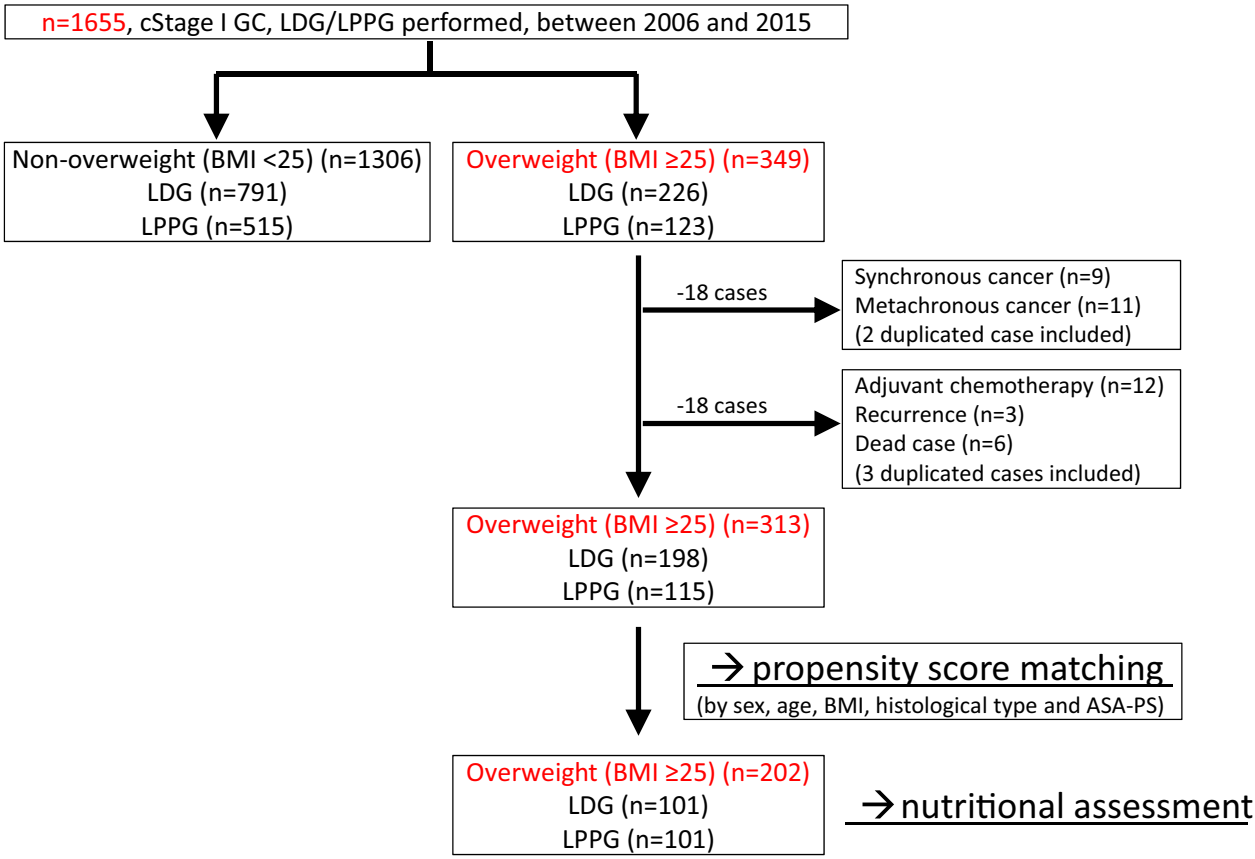


Data regarding clinical features and postoperative outcomes were collected from a prospectively maintained database in our institution and investigated retrospectively. This study was approved by the institutional review board at the Cancer Institute Hospital, Tokyo, Japan.

\section{Surgical procedure}

We performed LDG or LPPG for cStage I GC located in the middle to distal portion of the stomach. As described previously [8], our indication for LPPG was fulfillment of the following conditions: (1) preoperative diagnosis of intramucosal or submucosal carcinoma without lymph node metastasis; (2) patient age of 75 years or less; (3) tumor located in the middle third of the stomach and more than $5 \mathrm{~cm}$ from the pyloric ring; (4) any histological type; and (5) no hiatus hernia or esophageal reflux. In patients who met these conditions, LPPG was the first-choice procedure for cT1 N0 GC in the middle third of the stomach. The alternative procedure, LDG, was applied in the remaining cases.

All patients enrolled in this study underwent LDG or LPPG with modified D1 + or D2 lymphadenectomy. In LDG, modified D1 + lymphadenectomy (lymph node stations 1, 3a, $3 \mathrm{~b}, 4 \mathrm{sb}, 4 \mathrm{~d}, 5,6,7,8 \mathrm{a}, 9$, and 11p) was performed in patients with clinically diagnosed T1 N0 GC; D2 lymphadenectomy (lymph node stations 1, 3a, 3b, 4sb, 4d, 5, 6, 7, 8a, 9, 11p, 12a) was performed in patients with clinically diagnosed $T 1$ N1 or T2 N0 GC. In LPPG, because lymph node dissection of station \#5 and part of station \#6 was omitted to retain the blood supply of the pyloric cuff, as described in a previous report from our institution [8], modified D1 + lymphadenectomy (1, 3a, 3b, 4sb, 4d, 6, 7, 8a, 9, 11p) was performed for clinically diagnosed T1 N0 GC.

Extracorporeal/intracorporeal reconstructions were performed with Billroth I (B1) or Roux-en-Y (RY) procedures (for LDG) or gastrogastrostomy (for LPPG), according to tumor location, size of the remnant stomach and surgeons' preferences.

\section{Perioperative data and surveillance}

The demographic and clinicopathological data, including age, sex, BMI, ASA-PS, and short-term surgical results, were obtained from our database. The macroscopic and microscopic classification of tumors was based on the 3rd English edition of the Japanese Classification of Gastric Carcinoma [17] and the 7th edition of the International Union Against Cancer/American Joint Committee on Cancer TNM staging system [18]. Postoperative complications were categorized according to the Clavien-Dindo classification [19].

After gastrectomy, patients were followed according to the established protocol at our hospital, which included physical examination, blood tests and imaging examinations.
Body weight was regularly measured at hospital visits, and relative body weight ratio (postoperative/preoperative) was calculated for each patient using data collected from 1 to 2 years after surgery. Nutritional parameters, including serum total protein, albumin, prealbumin and hemoglobin, were also investigated at 6 months, 1 year and 2 years after surgery. Delta values for nutritional data (postoperative-preoperative) were calculated for each patient and compared between groups.

\section{Statistical analysis}

To compare clinical parameters between groups, the Chisquare test was used for categorical variables and the Student's $t$ test or Mann-Whitney $U$ test was used for continuous variables. Values are shown as mean \pm standard deviation or median (range). A $p$ value of $<0.05$ was considered statistically significant. Statistical analyses were conducted with JMP $^{\circledR} 11$ software (SAS Institute, Cary, NC, USA).

\section{Results}

\section{Patient and clinical characteristics}

The distribution of BMI for all 1655 patients is summarized in the histogram in Supplemental Fig. 1. Population characteristics before and after PSM are summarized in Table 1 . The rates of preoperative comorbidities (diabetes mellitus, hypertension, cerebrovascular disease, cardiovascular disease, pulmonary disease and reflux esophagitis) were compared between LDG and LPPG groups. After adjustment with PSM, there were no significant differences in any background characteristics between the groups. Among the LDG group after PSM, B1 and RY reconstructions were performed in 43 and 58 patients, respectively.

\section{Pathological results and surgical outcomes}

The pathological findings and operative results of the groups after PSM are shown in Table 2. Regarding pathological results, the LDG group showed significantly advanced $\mathrm{T}$ category compared with the LPPG group $(p=0.023)$. Extra-corporeal anastomosis was frequently performed in the LPPG group $(p=0.003)$. The two groups had comparable and acceptable short-term surgical outcomes. No significant differences were found between groups in operation time, blood loss or overall rate of postoperative complications. The rates of each postoperative event, such as anastomotic leakage, pancreatic fistula, intra-abdominal infectious complication and delayed gastric emptying, were not significantly different between two groups. No in-hospital mortality occurred in this case series. Iron drugs were used 
Table 1 Patient and clinical characteristics

\begin{tabular}{|c|c|c|c|c|c|c|}
\hline \multirow[t]{2}{*}{ Variable } & \multicolumn{2}{|c|}{$\begin{array}{l}\text { Overweight }(\mathrm{BMI} \geq 25) \\
\text { Non-matched patients }(n=313)\end{array}$} & \multirow[t]{2}{*}{$p$ value } & \multicolumn{2}{|c|}{$\begin{array}{l}\text { Overweight }(\mathrm{BMI} \geq 25) \\
\text { Matched patients }(n=202)\end{array}$} & \multirow[t]{2}{*}{$p$ value } \\
\hline & LDG $(n=198)$ & LPPG $(n=115)$ & & LDG $(n=101)$ & LPPG $(n=101)$ & \\
\hline \multicolumn{7}{|l|}{$\operatorname{Sex}, n(\%)$} \\
\hline Male & $157(79.3 \%)$ & $73(63.5 \%)$ & $p=0.002$ & $72(71.3 \%)$ & $71(70.3 \%)$ & $p=0.877$ \\
\hline Female & $41(20.7 \%)$ & $42(36.5 \%)$ & & $29(28.7 \%)$ & $30(29.7 \%)$ & \\
\hline Age (years) & $63.0 \pm 10.3$ & $58.4 \pm 9.6$ & $p<0.001$ & $59.4 \pm 11.1$ & $59.5 \pm 9.3$ & $\mathrm{p}=0.963$ \\
\hline Body weight, $\mathrm{kg}$ & $72.5 \pm 9.3$ & $72.7 \pm 9.9$ & $p=0.838$ & $72.7 \pm 10.0$ & $73.4 \pm 10.1$ & $\mathrm{p}=0.647$ \\
\hline $\mathrm{BMI}, \mathrm{kg} / \mathrm{m}^{2}$ & $27.0 \pm 2.0$ & $27.2 \pm 2.3$ & $p=0.462$ & $27.0 \pm 2.3$ & $27.1 \pm 2.3$ & $\mathrm{p}=0.720$ \\
\hline \multicolumn{7}{|l|}{ Histological type, $n(\%)$} \\
\hline Differentiated type ${ }^{a}$ & $101(51.0 \%)$ & $34(29.6 \%)$ & $p<0.001$ & $35(34.7 \%)$ & $34(33.7 \%)$ & $p=0.882$ \\
\hline Undifferentiated type $^{b}$ & $197(49.0 \%)$ & $81(70.4 \%)$ & & $66(65.3 \%)$ & $67(66.3 \%)$ & \\
\hline \multicolumn{7}{|l|}{ ASA-PS, $n(\%)$} \\
\hline I & $92(46.5 \%)$ & $55(48.8 \%)$ & $p=0.968$ & $47(46.5 \%)$ & $46(45.5 \%)$ & $p=0.826$ \\
\hline II & $104(52.5 \%)$ & $59(51.3 \%)$ & & $52(51.5 \%)$ & $54(53.5 \%)$ & \\
\hline III- & $2(1.0 \%)$ & $1(0.9 \%)$ & & $2(2.0 \%)$ & $1(1.0 \%)$ & \\
\hline \multicolumn{7}{|l|}{ Comorbidity, $n(\%)$} \\
\hline Diabetes mellitus & $15(7.6 \%)$ & $5(4.4 \%)$ & $p=0.260$ & $7(6.9 \%)$ & $5(5.0 \%)$ & $p=0.552$ \\
\hline Hypertension & $65(32.8 \%)$ & $39(33.9 \%)$ & $p=0.844$ & $33(32.7 \%)$ & $35(34.7 \%)$ & $p=0.766$ \\
\hline Cerebrovascular disease & $8(4.0 \%)$ & $2(1.7 \%)$ & $p=0.264$ & $3(3.0 \%)$ & $2(2.0 \%)$ & $p=0.651$ \\
\hline Cardiovascular disease & $14(7.1 \%)$ & $3(2.6 \%)$ & $p=0.093$ & $7(6.9 \%)$ & $3(3.0 \%)$ & $p=0.195$ \\
\hline Pulmonary disease & $12(6.1 \%)$ & $2(2.6 \%)$ & $p=0.168$ & $6(5.9 \%)$ & $2(2.0 \%)$ & $p=0.149$ \\
\hline Reflux esophagitis $^{c}$ & $12(6.1 \%)$ & $6(5.2 \%)$ & $p=0.757$ & $6(5.9 \%)$ & $5(5.0 \%)$ & $p=0.719$ \\
\hline \multicolumn{7}{|l|}{ Reconstruction, $n(\%)$} \\
\hline $\mathrm{B} 1$ & $79(39.9 \%)$ & - & & $43(42.6 \%)$ & - & \\
\hline RY & $110(60.1 \%)$ & - & & $58(57.4 \%)$ & - & \\
\hline Gastro-gastrostomy & - & $115(100 \%)$ & & - & $101(100 \%)$ & \\
\hline
\end{tabular}

Values are shown mean \pm standard deviation

$B M I$ body mass index, ASA-PS American Society of Anesthesiologists physical status, B1 Billroth I, RY Roux-en-Y

${ }^{a}$ Differentiated type refers to papillary adenocarcinoma, well-differentiated adenocarcinoma, and moderately differentiated adenocarcinoma

${ }^{\mathrm{b}}$ Undifferentiated type refers to poorly differentiated adenocarcinoma and signet ring cell carcinoma

${ }^{\mathrm{c}}$ Severer than Grade A esophagitis according to the Los Angeles classification. *

for postoperative anemia or iron deficiency in some cases after gastrectomy, as shown in Table 2 .

\section{Postoperative body weight change and nutritional status}

The postoperative body weight patterns of overweight patients are shown in Table 3 . The mean relative body weight ratios (postoperative/preoperative ratios) were $87.5 \pm 8.0 \%$ after LDG and $89.6 \pm 6.7 \%$ after LPPG (difference not significant; $p=0.088$ ). Postoperative median BMI values were less than $25 \mathrm{~kg} / \mathrm{m}^{2}$ in the both groups (difference not significant; $p=0.121$ ).

No significant differences were found between LDG and LPPG groups preoperatively in the four nutritional parameters compared (total protein, albumin, prealbumin and hemoglobin). Changes in nutritional data (postoperative-preoperative) were calculated for each patient and compared in postoperative analysis. Prealbumin level at 2 years and hemoglobin levels at 6 months, 1 year and 2 years were significantly well maintained after LPPG (Fig. 2). Of note, prealbumin and hemoglobin levels at 2 years had almost returned to baseline levels in the overweight LPPG group.

Two different reconstruction methods, such as B1 and RY, were included in the LDG group. Therefore, the comparisons between LPPG and DG with each reconstruction pattern were additionally analyzed. In comparison between LDGB1 $(n=43)$ and LPPG $(n=101)$, hemoglobin levels at 1 year and 2 years were significantly well maintained in the LPPG group (Fig. 3a). In comparison between LDGRY $(n=58)$ and LPPG $(n=101)$, prealbumin level at 2 years and hemoglobin levels at 6 months, 1 year and 2 years were significantly well maintained in the LPPG group (Fig. 3b). 
Table 2 Pathological results and surgical outcomes

\begin{tabular}{|c|c|c|c|}
\hline \multirow[t]{2}{*}{ Variable } & \multicolumn{2}{|c|}{$\begin{array}{l}\text { Overweight }(\mathrm{BMI} \geq 25) \\
\text { Matched patients }(n=202)\end{array}$} & \multirow[t]{2}{*}{$p$ value } \\
\hline & LDG $(n=101)$ & LPPG $(n=101)$ & \\
\hline \multicolumn{4}{|l|}{ pT category, $n(\%)$} \\
\hline $\mathrm{T} 1 \mathrm{a}(\mathrm{M})$ & $40(39.6 \%)$ & $51(50.5 \%)$ & \multirow[t]{3}{*}{$p=0.023$} \\
\hline $\mathrm{T} 1 \mathrm{~b}(\mathrm{SM})$ & $48(47.5 \%)$ & $47(46.5 \%)$ & \\
\hline T2- (MP-) & $13(12.9 \%)$ & $3(3.0 \%)$ & \\
\hline \multicolumn{4}{|l|}{ pN category, $n(\%)$} \\
\hline No & $92(91.1 \%)$ & $91(90.1 \%)$ & \multirow[t]{2}{*}{$p=0.810$} \\
\hline N1- & $9(8.9 \%)$ & $10(9.9 \%)$ & \\
\hline \multicolumn{4}{|l|}{ Anastomosis, $n(\%)$} \\
\hline Extra-corporeal & $56(55.4 \%)$ & $76(75.2 \%)$ & \multirow[t]{2}{*}{$p=0.003$} \\
\hline Intra-corporeal & $45(44.6 \%)$ & $25(24.8 \%)$ & \\
\hline Number of resected lymph nodes & $38(19-121)$ & $39(13-84)$ & $p=0.789$ \\
\hline Operation time $(\min )$ & $268(160-515)$ & $254(78-368)$ & $p=0.246$ \\
\hline Blood loss (g) & $45(0-440)$ & $35(0-400)$ & $p=0.522$ \\
\hline \multicolumn{4}{|l|}{ Postoperative complications, $n(\%)^{\mathrm{a}}$} \\
\hline No complication/Grade I & $86(85.1 \%)$ & $80(79.2 \%)$ & \multirow[t]{3}{*}{$p=0.424$} \\
\hline Grade II & $9(8.9 \%)$ & $15(14.9 \%)$ & \\
\hline Grade IIIa- & $6(5.9 \%)$ & $6(5.9 \%)$ & \\
\hline Anastomotic leakage, $n(\%)^{\mathrm{b}}$ & $1(1.0 \%)$ & $1(1.0 \%)$ & $p=1.000$ \\
\hline Pancreatic fistula, $n(\%)^{\mathrm{b}}$ & $1(1.0 \%)$ & $1(1.0 \%)$ & $p=1.000$ \\
\hline $\begin{array}{l}\text { Intra-abdominal infectious complication, } \\
n(\%)^{\mathrm{b}}\end{array}$ & $5(5.0 \%)$ & $9(8.9 \%)$ & $p=0.268$ \\
\hline Delayed gastric emptying, $n(\%)$ & $1(1.0 \%)$ & $3(3.0 \%)$ & $p=0.313$ \\
\hline Postoperative hospital stay (day) & $10(8-54)$ & $11(7-35)$ & $p=0.078$ \\
\hline In-hospital mortality, $n(\%)$ & $0(0 \%)$ & $0(0 \%)$ & - \\
\hline \multicolumn{4}{|l|}{ Postoperative iron drug usage, $n(\%)$} \\
\hline Yes & $4(4.0 \%)$ & $2(2.0 \%)$ & \multirow[t]{2}{*}{$p=0.407$} \\
\hline No & $97(96.0 \%)$ & $99(98.0 \%)$ & \\
\hline
\end{tabular}

Values are shown as median (range)

$M$ mucosa, $S M$ submucosa, $M P$ muscularis propria

${ }^{a}$ According to the Clavien-Dindo classification

${ }^{\mathrm{b}}$ Severer than Grade 2 complications according to the Clavien-Dindo classification

Table 3 Postoperative body weight change

\begin{tabular}{llll}
\hline Relative body weight & Preoperative & $p$ value & Postoperative (1-2 years) \\
\hline Overweight LDG & $100 \%$ & - & $87.5 \pm 8.0 \%$ \\
Overweight LPPG & $100 \%$ & $89.6 \pm 6.7 \%$ \\
\hline BMI & Preoperative & $p$ value & Postoperative (1-2 years) $p$ value \\
\hline Overweight LDG & $27.0 \pm 2.3$ & $p=0.720$ & $23.8 \pm 2.9$ \\
Overweight LPPG & $27.1 \pm 2.3$ & & $24.5 \pm 2.8$ \\
\hline
\end{tabular}

Values are shown mean \pm standard deviation

\section{Discussion}

In the current study, we addressed the following clinical question, "Should PPG be performed in overweight/ obese patients?" Because PPG is an alternative to DG for early gastric cancer in the middle third of the stomach, we designed our comparison of the procedures to resolve 
this question after adjusting for patient characteristics with PSM.

We have reported that postoperative body weight loss after LPPG was $6.76 \%$ on average including non-overweight and overweight patients [8]. In this study, overweight/obese patients lost an average of more than $10 \%$ of body weight after LPPG; this weight loss was similar to that after LDG. Previous studies have shown that overweight/obese patients tend to lose a higher proportion of body weight than nonoverweight/non-obese patients after standard curative resection of GC, such as distal or total gastrectomy $[15,16]$. The present study focused on body weight change following a function-preserving procedure, $\mathrm{PPG}$, in which body weight is generally expected to be well maintained. Our results can be explained by the fact that substantial body weight loss occurs regardless of the type of gastrectomy in overweight/ obese patients. The clinical importance of preoperative BMI and postoperative body weight loss has been widely

$$
\begin{gathered}
\text { BMI } \geq 25 \\
\text { Delta value }=(\text { postope }) \text {-(preope) }
\end{gathered}
$$
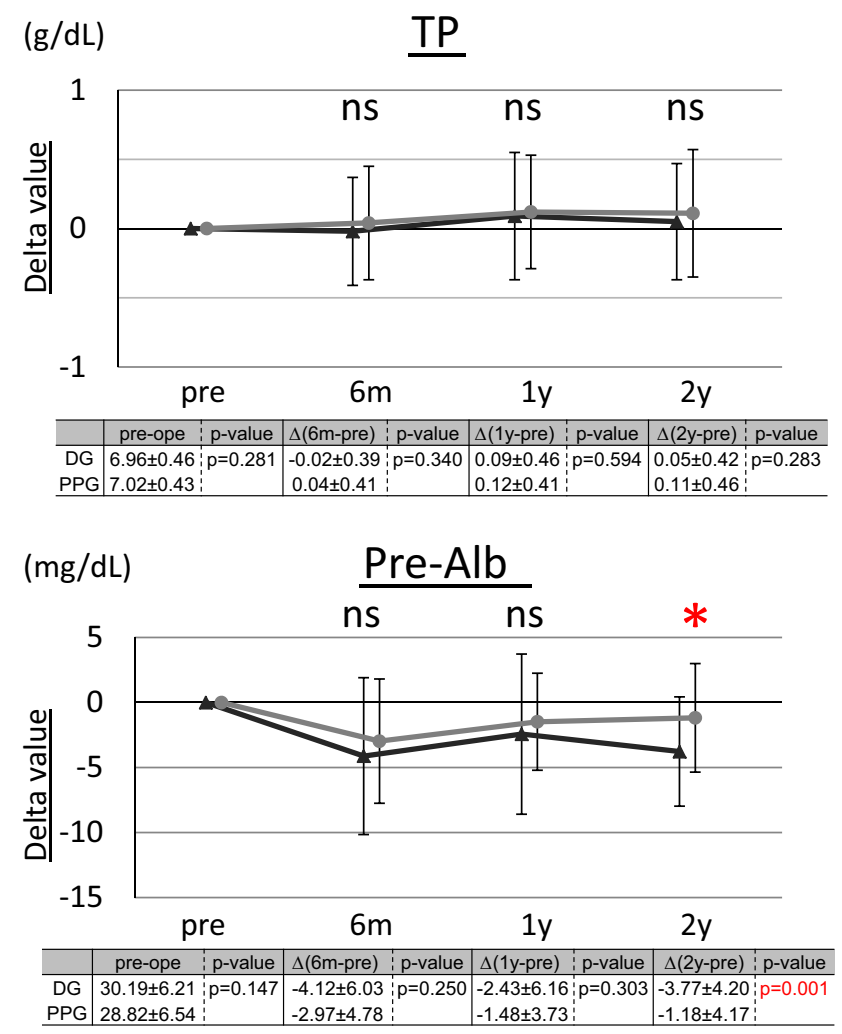

\section{Figure 2}

Fig. 2 Postoperative nutritional assessment of LDG and LPPG; the nutritional comparison between the overweight LDG group $(n=101)$ and the overweight LPPG group $(n=101)$ was conducted using a
Fig. 3 Postoperative nutritional assessment of LDGB1/LDGRY and LPPG; a The comparison between the overweight LDGB1 group $(n=43)$ and the overweight LPPG group $(n=101)$. b The comparison between the overweight LDGRY group $(n=58)$ and the overweight LPPG group $(n=101)$. The comparisons were conducted using a delta value (postoperative-preoperative). TP total protein, $A l b$ albumin, Pre-Alb prealbumin, $H b$ hemoglobin, ${ }^{*} p<0.05$

discussed; these parameters are reported to be associated with survival outcomes and continuation of systemic chemotherapy for GC $[15,20,21]$. Thus, it is important to acknowledge different patterns according to body composition and BMI. To our knowledge, this is the first study to compare nutritional status and weight loss between PPG and DG in an overweight/obese cohort and to clearly evaluate substantial postoperative weight loss after PPG in this cohort.

This study confirmed the superiority of LPPG for maintaining certain postoperative nutritional parameters. Although the nutritional status of patients was similar after
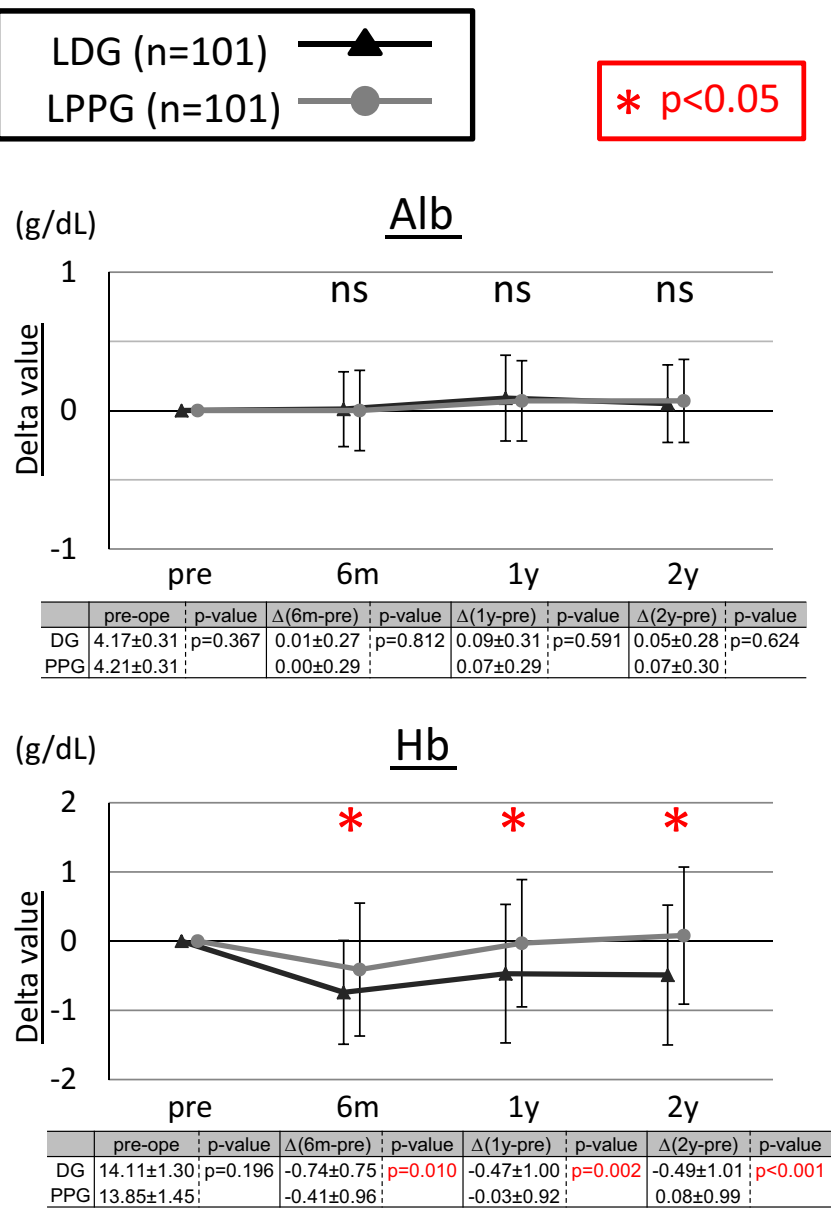

delta value (postoperative-preoperative). $T P$ total protein, $A l b$ albumin, Pre-Alb prealbumin, $H b$ hemoglobin, ${ }^{*} p<0.05$ 
a

BMI $\geq 25$
Delta value=(postope)-(preope)

$(\mathrm{g} / \mathrm{dL})$

$\underline{T P}$
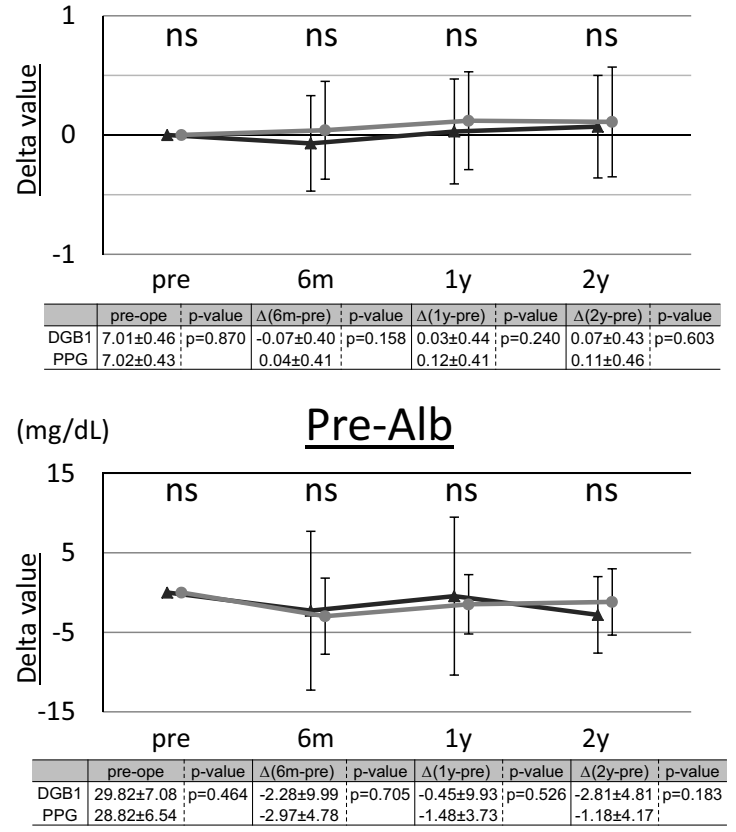

b

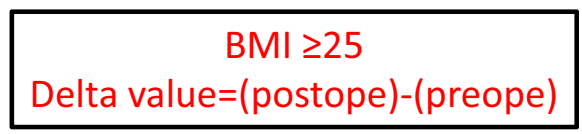

(g/dL) $\quad \underline{T P}$
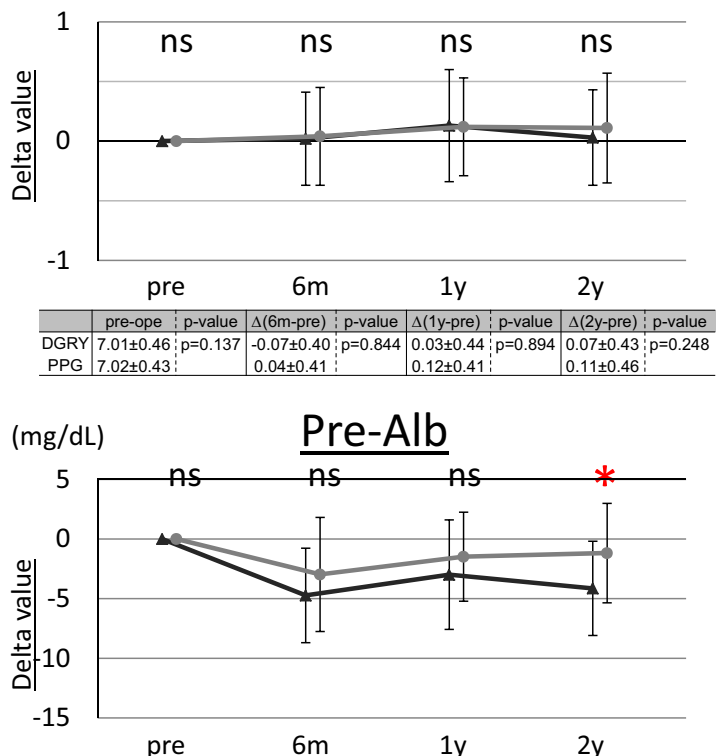

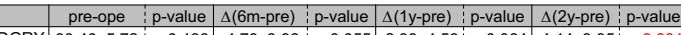
\begin{tabular}{l|l:l|l|l|l|l|l|l}
\hline DGRY & $30.40 \pm 5.72$ & $\mathrm{p}=0.133$ & $-4.73 \pm 3.96$ & $\mathrm{p}=0.055$ & $-2.99 \pm 4.59$ & $\mathrm{p}=0.064$ & $-4.14 \pm 3.95$ & $\mathrm{p}<0.00$
\end{tabular} \begin{tabular}{l|l} 
PPG & $28.82 \pm 6.54$ \\
\hline
\end{tabular}

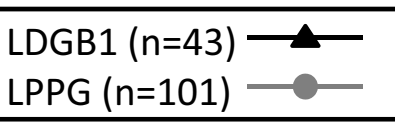

$* p<0.05$

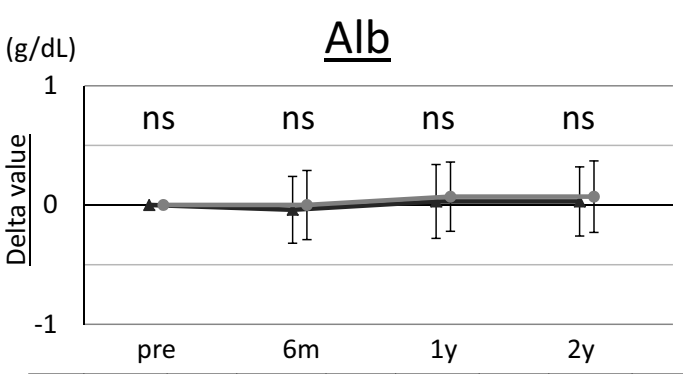

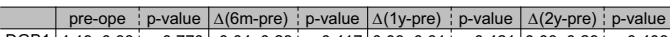

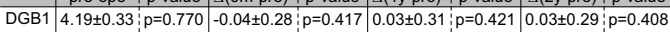
\begin{tabular}{l|l|l|l|l|l} 
PPG $4.21 \pm 0.31$ & $0.00 \pm 0.29$ & $0.07 \pm 0.29$ & $0.07 \pm 0.30$ \\
\hline
\end{tabular}

(g/dL) $\quad \underline{\mathrm{Hb}}$

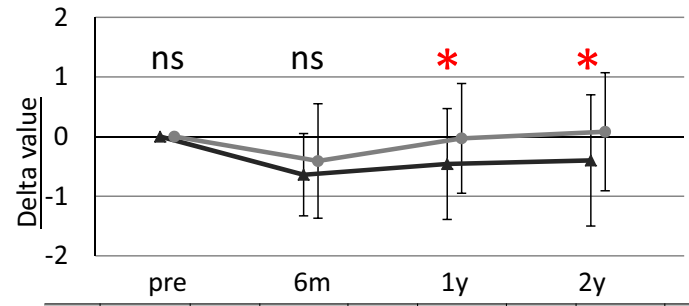

\begin{tabular}{l|c|c|c|c|c|c|c|c} 
& pre-ope & $p$-value & $\Delta(6 \mathrm{~m}$-pre) & $p$-value & $\Delta(1 y$-pre) & $p$-value & $\Delta$ (2y-pre) & $p$-value \\
\hline
\end{tabular}

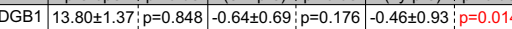

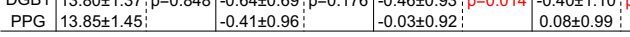
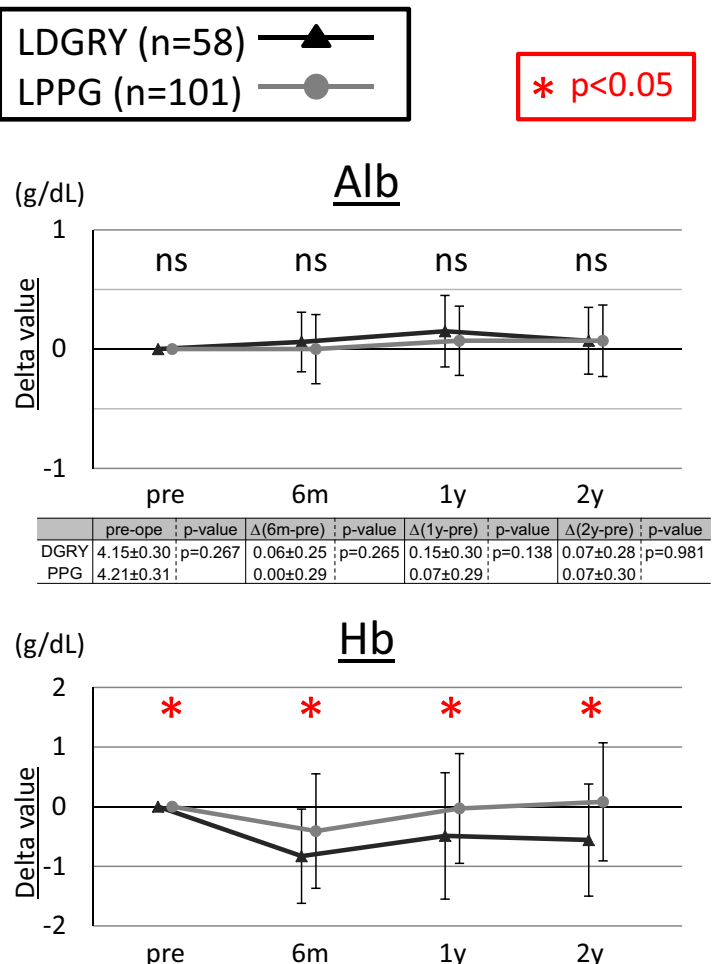

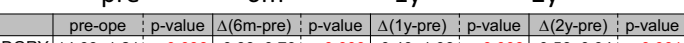

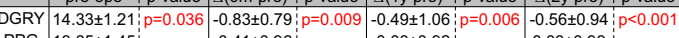
\begin{tabular}{l|l|l|l|l|l|} 
PPG & $13.85 \pm 1.45:$ & $-0.41 \pm 0.96:$ & $-0.49 \pm \pm 0.92$ & $p=0.006$ & $-0.56 \pm 0.94$ \\
\hline
\end{tabular} 
LPPG and LDG (except for prealbumin level 2 years postoperatively) significantly higher hemoglobin levels were confirmed in the LPPG group at 6 months, 1 year and 2 years, indicating an apparent benefit for anemia. Prealbumin has a short half-life (about 2 days) and is a sensitive nutritional marker; its usefulness has been reported in several clinical settings [22-25]. Friedrich et al. [26] confirmed both pronounced body muscle loss and prealbumin loss after laparoscopic sleeve gastrectomy for a bariatric purpose, suggesting a correlation between body composition change and prealbumin status. The stability of prealbumin levels after LPPG may indicate the potential nutritional benefits of the procedure in overweight/obese patients.

The reasons for postgastrectomy anemia are multifactorial and include the altered alimentary tract, impaired food intake/absorption, reduced gastric intrinsic factor, and inadequate $\mathrm{pH}$ balance of the remnant stomach [27]. Compared with conventional DG, PPG preserves gastric acid secretion and longer retention time in the remnant stomach, resulting in an appropriate conversion of ingested ferric iron to absorbable ferrous iron after mixture with gastric acid [28, 29]. As expected, the postoperative hemoglobin levels were well maintained and were significantly higher after LPPG than after LDG at each time point.

The main limitation of the present study is its nonrandomized retrospective design. To resolve this limitation, we conducted an adjustment with PSM, resulting in no significant differences in patient characteristics between groups.

Other possible limitation is a mixture of two reconstruction methods, such as B1 and RY procedures, in the LDG group. The previous randomized clinical trial by Hirao et al. [30] showed no significant differences only in serum albumin and lymphocyte count between DGB1 and DGRY. Regarding iron status and postoperative anemia, the superiority of DGB1 has been previously suggested [31-33]. In comparison of four nutritional parameters (total protein, albumin, prealbumin and hemoglobin) between DGB1 $(n=43)$ and DGRY $(n=58)$ in the current case series, no significant differences were observed (data not shown). The comparisons between LPPG and LDG with each reconstruction procedure were additionally analyzed in our study. As a result, the superiority of LPPG in the hemoglobin level over both LDGB1 and LDGRY was indicated (Fig. 3a, b). However, reconstruction methods after DG can have various influences in terms of postoperative food passage and nutritional status, which should be always minded in a clinical trial.

Finally, ethnic and regional variations regarding physique and baseline BMI are also possible problems. We set a BMI of $25 \mathrm{~kg} / \mathrm{m}^{2}$ as the cutoff point, considering the distribution pattern of Japanese patients in the current study (Supplemental Fig. 1). The rates of overweight and obesity differ widely between Asian and Western countries [10]. Furthermore, a World Health Organization expert group has recommended population-specific BMI cut-off points for overweight and obesity [34]. The applicability of our results for Western populations needs to be assessed carefully; a different BMI cutoff may be needed in these populations.

In this study, we first clarified nutritional status and weight loss patterns following LPPG in overweight/obese patients by comparing LPPG results with those of LDG. For overweight/obese patients, LDG and LPPG resulted in similar degrees of postoperative weight loss, with patients achieving near-ideal body weight levels; the postoperative nutritional advantages of LPPG were also confirmed. We plan to further evaluate improvements in lifestyle-related diseases such as hypertension and diabetes mellitus, body composition changes, and postoperative quality of life with a questionnaire-based study in the near future.

\section{Conclusions}

LPPG seemed to be better even for overweight/obese patients who meet indication criteria. A study of the subsequent clinical benefits of LPPG is required to reinforce our current results.

Acknowledgements No grant support or institutional/corporate affiliations are associated with this study.

\section{References}

1. Japanese Gastric Cancer Association. Japanese gastric cancer treatment guidelines 2010 (ver. 3). Gastric Cancer. 2011;14:113-23.

2. Hotta T, Taniguchi K, Kobayashi Y, Johata K, Sahara M, Naka T, et al. Postoperative evaluation of pylorus-preserving procedures compared with conventional distal gastrectomy for early gastric cancer. Surg Today. 2001;31:774-9.

3. Yamaguchi T, Ichikawa D, Kurioka H, Ikoma H, Koike H, Otsuji E, et al. Postoperative clinical evaluation following pylorus-preserving gastrectomy. Hepatogastroenterology. 2004;51:883-6.

4. Park do J, Lee HJ, Jung HC, Kim WH, Lee KU, Yang HK. Clinical outcome of pylorus-preserving gastrectomy in gastric cancer in comparison with conventional distal gastrectomy with Billroth I anastomosis. World J Surg. 2008;32:1029-36.

5. Suh YS, Han DS, Kong SH, Kwon S, Shin CI, Kim WH, et al. Laparoscopy-assisted pylorus-preserving gastrectomy is better than laparoscopy-assisted distal gastrectomy for middle-third early gastric cancer. Ann Surg. 2014;259:485-93.

6. Nunobe S, Sasako M, Saka M, Fukagawa T, Katai H, Sano T. Symptom evaluation of long-term postoperative outcomes after pylorus-preserving gastrectomy for early gastric cancer. Gastric Cancer. 2007;10:167-72.

7. Fujita J, Takahashi M, Urushihara T, Tanabe K, Kodera Y, Yumiba T, et al. Assessment of postoperative quality of life following pylorus-preserving gastrectomy and Billroth-I distal gastrectomy in gastric cancer patients: results of the nationwide 
postgastrectomy syndrome assessment study. Gastric Cancer. 2016;19:302-11.

8. Tsujiura M, Hiki N, Ohashi M, Nunobe S, Kumagai K, Ida S, et al. Excellent long-term prognosis and favorable postoperative nutritional status after laparoscopic pylorus-preserving gastrectomy. Ann Surg Oncol. 2017;24:2233-2240.

9. NCD Risk Factor Collaboration (NCD-RisC). Trends in adult body-mass index in 200 countries from 1975 to 2014: a pooled analysis of 1698 population-based measurement studies with 19.2 million participants. Lancet. 2016;387:1377-96.

10. Finucane MM, Stevens GA, Cowan MJ, Danaei G, Lin JK, Paciorek CJ, et al. National, regional, and global trends in bodymass index since 1980: systematic analysis of health examination surveys and epidemiological studies with 960 country-years and 9.1 million participants. Lancet. 2011;377:557-67.

11. Malik VS, Willett WC, Hu FB. Global obesity: trends, risk factors and policy implications. Nat Rev Endocrinol. 2013;9:13-27.

12. Egger G, Dixon J. Obesity and chronic disease: always offender or often just accomplice? Br J Nutr. 2009;102:1238-42.

13. Evert AB, Riddell MC. Lifestyle intervention: nutrition therapy and physical activity. Med Clin N Am. 2015;99:69-85.

14. Kushner RF, Ryan DH. Assessment and lifestyle management of patients with obesity: clinical recommendations from systematic reviews. JAMA. 2014;312:943-52.

15. Kong F, Li H, Fan Y, Zhang X, Cao S, Yu J, et al. Overweight patients achieve ideal body weight following curative gastrectomy resulting in better long-term prognosis. Obes Surg. 2013;23:650-6.

16. Davis JL, Selby LV, Chou JF, Schattner M, Ilson DH, Capanu M, et al. Patterns and predictors of weight loss after gastrectomy for cancer. Ann Surg Oncol. 2016;23:1639-45.

17. Japanese Gastric Cancer Association. Japanese classification of gastric carcinoma: 3rd English edition. Gastric Cancer. 2011;14:101-12.

18. Sobin L, Gospodarowicz MK, Wittekind C, editors. International Union Against Cancer TNM classification of malignant tumours. 7th ed. Oxford: Wiley; 2009.

19. Dindo D, Demartines N, Clavien PA. Classification of surgical complications: a new proposal with evaluation in a cohort of 6336 patients and results of a survey. Ann Surg. 2004;240:205-13.

20. Lee SE, Lee JH, Ryu KW, Nam B, Kim CG, Park SR, et al. Changing pattern of postoperative body weight and its association with recurrence and survival after curative resection for gastric cancer. Hepatogastroenterology. 2012;59:430-5.

21. Aoyama T, Yoshikawa T, Shirai J, Hayashi T, Yamada T, Tsuchida $\mathrm{K}$, et al. Body weight loss after surgery is an independent risk factor for continuation of S-1 adjuvant chemotherapy for gastric cancer. Ann Surg Oncol. 2013;20:2000-6.

22. Devoto G, Gallo F, Marchello C, Racchi O, Garbarini R, Bonassi $\mathrm{S}$, et al. Prealbumin serum concentrations as a useful tool in the assessment of malnutrition in hospitalized patients. Clin Chem. 2006;52:2281-5.

23. Delliere $\mathrm{S}$, Cynober L. Is transthyretin a good marker of nutritional status? Clin Nutr. 2017;36:364-70.

24. Zhou J, Hiki N, Mine S, Kumagai K, Ida S, Jiang X, et al. Role of prealbumin as a powerful and simple index for predicting postoperative complications after gastric cancer surgery. Ann Surg Oncol. 2017;24:510-7.

25. Bae HJ, Lee HJ, Han DS, Suh YS, Lee YH, Lee HS, et al. Prealbumin levels as a useful marker for predicting infectious complications after gastric surgery. J Gastrointest Surg. 2011;15:2136-44.

26. Friedrich AE, Damms-Machado A, Meile T, Scheuing N, Stingel $\mathrm{K}$, Basrai M, et al. Laparoscopic sleeve gastrectomy compared to a multidisciplinary weight loss program for obesity-effects on body composition and protein status. Obes Surg. 2013;23:1957-65.

27. Annibale B, Capurso G, Delle Fave G. The stomach and iron deficiency anaemia: a forgotten link. Dig Liver Dis. 2003;35:288-95.

28. Imada T, Rino Y, Takahashi M, Suzuki M, Tanaka J, Shiozawa $\mathrm{M}$, et al. Postoperative functional evaluation of pylorus-preserving gastrectomy for early gastric cancer compared with conventional distal gastrectomy. Surgery. 1998;123:165-70.

29. Kodama M, Koyama K, Chida T, Arakawa A, Tur G. Early postoperative evaluation of pylorus-preserving gastrectomy for gastric cancer. World J Surg. 1995;19:456-60 (discussion 61).

30. Hirao M, Takiguchi S, Imamura H, Yamamoto K, Kurokawa Y, Fujita J, et al. Comparison of Billroth I and Roux-en-Y reconstruction after distal gastrectomy for gastric cancer: one-year postoperative effects assessed by a multi-institutional RCT. Ann Surg Oncol. 2013;20:1591-7.

31. Toyomasu Y, Ogata K, Suzuki M, Yanoma T, Kimura A, Kogure $\mathrm{N}$, et al. Comparison of the physiological effect of Billroth-I and Roux-en-Y reconstruction following laparoscopic distal gastrectomy. Surg Laparosc Endosc Percutan Tech. 2018;28:328-33.

32. Imamura $\mathrm{T}$, Komatsu $\mathrm{S}$, Ichikawa D, Kosuga T, Okamoto K, Konishi $\mathrm{H}$, et al. Reconstruction method as an independent risk factor for the postoperative decrease in hemoglobin in stage I gastric cancer. J Gastroenterol Hepatol. 2016;31:959-64.

33. Lee JH, Hyung WJ, Kim HI, Kim YM, Son T, Okumura N, et al. Method of reconstruction governs iron metabolism after gastrectomy for patients with gastric cancer. Ann Surg. 2013;258:964-9.

34. WHO Expert Consultation. Appropriate body-mass index for Asian populations and its implications for policy and intervention strategies. Lancet. 2004;363:157-63.

Publisher's Note Springer Nature remains neutral with regard to jurisdictional claims in published maps and institutional affiliations. 